\title{
Ações culturais em museus para pessoas privadas de liberdade do sistema carcerário $^{1}$
}

\section{Cultural actions in museums for people deprived of freedom in the prison system}

DOI: 10.46814/lajdv3n5-041

Recebimento dos originais: $01 / 05 / 2021$

Aceitação para publicação: 31/06/2021

\section{Christiane Maria Castellen}

Christiane Maria Castellen: Licenciada em Educação Artística, com Habilitação em Artes Plásticas e Especialista no Ensino das Artes Visuais / UDESC. Atuou na Fundação Catarinense de Cultura, na função de Educadora do Núcleo de Ação Educativa do Museu Histórico de Santa Catarina Palácio Cruz e Sousa - MHSC (2009-2018). Desenvolveu ações educativas no Museu da Imagem e do Som de Santa Catarina - MIS/SC (2012-2013). Coordenadora do Núcleo de Arte Educação do Museu de Arte de Santa Catarina - MASC (1996 a 2009). Autora do livro "CONSTRUINDO Ações Culturais em Museus: O patrimônio cultural na reintegração social de pessoas privadas de liberdade". Membro da

Rede de Educadores em Museus de Santa Catarina e do Grupo de Pesquisa Educação, Arte e Inclusão. UDESC - Cnpq.

E-mail: cmcastellen@gmail.com

\section{RESUMO}

O presente artigo pretende contribuir nas reflexões e na produção teórica do campo das políticas culturais, quanto à realização de projetos e programas de ações educativas e culturais de inclusão sociocultural, que promovam a reintegração social de indivíduos submetidos ao regime de privação de liberdade. Apresenta o Projeto CONSTRUINDO, realizado pelo Museu Histórico de Santa Catarina, entre os anos de 2009 e 2018, e seu desdobramento no Museu da Imagem e do Som de Santa Catarina e no Museu de Arte de Santa Catarina - unidades culturais vinculadas à Fundação Catarinense de Cultura. O Projeto teve como objetivo promover o acesso e a reintegração de um grupo de detentos da Penitenciária Estadual de Florianópolis, através de ações educativas socioculturais em visitas mensais nas exposições.

Palavras-chave: pessoas em privação de liberdade; ação cultural em museus; educação patrimonial; reintegração social.

\begin{abstract}
This article aims to contribute to the reflections and theoretical production in the field of cultural policies, regarding the realization of projects and programs of educational and cultural actions of sociocultural inclusion, which promote the social reintegration of individuals subjected to the regime of deprivation of liberty. It presents the CONSTRUINDO Project, carried out by the Museu Histórico de Santa Catarina, between the years 2009 and 2018, and its unfolding in the Museu da Imagem e do Som de Santa Catarina and in the Museu de Arte de Santa Catarina - cultural units linked to the Fundação Catarinense de Cultura. The Project aimed to promote the access and reintegration of a group

\footnotetext{
${ }^{1}$ Este texto foi atualizado, baseado e em parte extraído do artigo "Ações Culturais em Museus para Pessoas Privadas de Liberdade: Projeto CONSTRUINDO”, publicado nos Anais do VII Seminário Internacional de Políticas Culturais no ano de 2016, da Fundação Casa de Rui Barbosa.
} 
of inmates from the State Penitentiary of Florianópolis, through socio-cultural educational actions in monthly visits to the exhibitions.

Keywords: people in prison; cultural action in museums; heritage education; social reintegration.

\section{INTRODUÇÃO}

O presente artigo pretende subsidiar o desenvolvimento de estudos, quanto à realização de políticas culturais de inclusão sociocultural, que promovam a reintegração social de indivíduos submetidos ao regime de privação de liberdade. O texto apresenta as ações educativas e culturais de inclusão sociocultural do Projeto CONSTRUINDO - desenvolvido pelo Núcleo de Ação Educativa do Museu Histórico de Santa Catarina com o objetivo de promover o acesso de um grupo de detentos da Penitenciária Estadual de Florianópolis ao patrimônio cultural de três museus vinculados à Fundação Catarinense de Cultura: Museu Histórico de Santa Catarina (MHSC), Museu da Imagem e do Som de Santa Catarina (MIS/SC) e Museu de Arte de Santa Catarina (MASC). O projeto realizado entre os anos de 2009 a 2018 buscou oportunizar experiências, percepções, descobertas e apropriações da pluralidade de sentidos e narrativas presentes nos espaços dos museus, para esse grupo de homens, por meio de visitas às exposições, realizadas através de encontros mensais. O referido Projeto enfatizou a importância do acesso ao patrimônio cultural e da educação patrimonial como instrumentos de reintegração social e inclusão sociocultural para sujeitos privados de liberdade.

Sujeitos em privação de liberdade são reconhecidos como presos, presidiários, apenados, detentos ou reeducandos, e são aqueles que cumprem pena de detenção em decorrência de sentença condenatória ${ }^{2}$. A população carcerária, estando em um lugar condicionado e restrito à vigilância, é, muitas vezes, invisibilizada à sociedade, salvo nas projeções midiáticas de situações conflituosas no sistema prisional.

É possível que uma das questões mais complexas da realidade social brasileira, na atualidade, possa ser identificada na situação carcerária. De acordo com os relatórios do Sistema de Informação do Departamento Penitenciário Nacional (Sisdepen) ${ }^{3}$, realizados pelo Departamento Penitenciário

\footnotetext{
${ }^{2}$ Cabe esclarecer que o termo "reeducando" norteou o Projeto CONSTRUINDO, em função de ele apresentar-se em documentos contratuais entre as instituições parceiras citadas neste relato e considerando o Conselho Nacional de Justiça (CNJ) como referência. É um termo controverso, tanto para estudiosos da área como entre os sujeitos que encontram-se na condição de privação de liberdade. http://www.jusbrasil.com.br/topicos/301646/reeducando.

${ }^{3}$ SISDEPEN é a plataforma de estatísticas do sistema penitenciário brasileiro que sintetiza as informações sobre os estabelecimentos penais e a população carcerária. Em 2017, substituiu e reformulou a metodologia utilizada pelo INFOPEN - sistema de informações estatísticas do sistema penitenciário brasileiro. O levantamento traz informações de todas as unidades prisionais brasileiras, incluindo dados de infraestrutura, recursos humanos, vagas, gestão, assistências, população prisional, perfil dos presos, entre outros. Os dados são periodicamente atualizados pelos gestores das unidades prisionais desde 2004. Acompanho os índices nos diferentes relatórios apresentados pelo INFOPEN desde o ano de 2014. Mas ainda no ano de 2020 o DEPEN lança o relatório nominado como INFOPEN de dezembro de 2019.
} 
Nacional (Depen) / Ministério da Justiça, o Brasil passou de quarta maior população prisional para a terceira, ultrapassando a Rússia e ficando atrás apenas dos Estados Unidos e China. No país existem 1.393 unidades prisionais ${ }^{4}$, cuja população carcerária totaliza 811.707 pessoas em regime de privação de liberdade ${ }^{5}$. De acordo com os relatórios apresentados, as unidades exibem taxa de ocupação superior a $100 \%$, e em um espaço concebido para custodiar 10 pessoas existem por volta de 15 a 16 indivíduos encarcerados.

Segundo o último levantamento referente ao período de julho a dezembro de 2020, o perfil das pessoas presas do sistema penitenciário brasileiro (excluindo-se as prisões) é majoritariamente: de jovens $(42,63 \%)^{6}$, de pardas $(49,92 \%)$, brancas $(32,9 \%)$, pretas $(16 \%)^{7}$. O referido relatório não contempla informações sobre a escolaridade, a renda e o estado civil das pessoas presas, que em anos anteriores apresentaram ter grande percentual de pessoas de baixa escolaridade, de baixa renda e solteiras. Com relação ao total prisional por gênero, 95,71\% das pessoas presas são masculinas e 4,29\% são femininas. O crime contra o patrimônio (roubo e furto) corresponde a 40,91\% das incidências penais, seguido de $\operatorname{drogas}^{8}$ 29,9\% (BRASIL, 2021), sendo que neste último não há distinção entre tráfico e portabilidade.

Tais índices abafam conflitos socioculturais, que merecem profundas reflexões e vão além das discussões sobre Direitos Humanos, Segurança Pública, direito à Justiça, combate à criminalidade. Reflexões e ações que pertencem a toda a sociedade, e cuja problemática exige a atuação de gestores públicos, legisladores e operadores jurídicos, na condução e construção de caminhos mais encorajadores, tanto para a população carcerária como para a sociedade em geral.

Levantamentos disponíveis em:

https://www.gov.br/depen/pt-br/sisdepen/mais-informacoes/relatorios-infopen

http://dados.mj.gov.br/dataset/infopen-levantamento-nacional-de-informacoes-penitenciarias

https://www.gov.br/depen/pt-br/assuntos/noticias/depen-lanca-infopen-com-dados-de-dezembro-de-2019

${ }^{4}$ Dados do Sistema Prisional em Números do ano de 2019 - $3^{\circ}$ trimestre. Consta no levantamento os seguintes números: Cadeia Pública (556); Casa do Albergado (36); Centro de Observação Criminológica/Remanejo (18); Colônia Agrícola, Industrial ou similar (92); Hospital de Custódia e Tratamento Psiquiátrico (30); Penitenciaria (661).

Disponível em: https://www.cnmp.mp.br/portal/relatoriosbi/sistema-prisional-em-numeros

${ }^{5}$ Dados do Relatório do INFOPEN período de julho a dezembro de 2020, Atualizado em 10/08/2021. Inclui-se neste número os presos sob a tutela do Sistema Penitenciário e também os presos em Prisões (que estão sob a custódia das Polícias Judiciais, Batalhões de Polícias e Bombeiros Militares). Não consta neste número, as 139.010 pessoas que estão em Prisão Domiciliar, com e sem monitoramento eletrônico. Disponível em: https://www.gov.br/depen/pt-br/sisdepen acesso em 03/0/2021.

${ }^{6}$ O Relatório do INFOPEN informa que são considerados jovens, pessoas entre 18 e 29 anos, de acordo com o Estatuto da Juventude (BRASIL, 2014, p. 48)

${ }^{7}$ Nos Relatórios do INFOPEN dos anos de 2014 e 2015, as informações quanto aos dados acerca da raça/cor, encontravase na categoria "negra" (índice majoritário) desdobrada para "parda" e "preta" em relatórios nos anos posteriores. https://www.gov.br/depen/pt-br/assuntos/noticias/infopen-levantamento-nacional-de-informacoes-penitenciarias-

2016/relatorio_2016_22111.pdf

${ }^{8}$ Lei 11.343/06 - Art. 33. Importar, exportar, remeter, preparar, produzir, fabricar, adquirir, vender, expor à venda, oferecer, ter em depósito, transportar, trazer consigo, guardar, prescrever, ministrar, entregar a consumo ou fornecer drogas, ainda que gratuitamente, sem autorização ou em desacordo com determinação legal ou regulamentar. 
A magnitude da situação, segundo o Depen, exige a intensificação de esforços e o envolvimento dos três poderes da República, em todos os níveis da Federação, em busca de soluções e estratégias inteligentes para equacionar os problemas existentes. O Depen ao propor no ano de 2014 uma política nacional de melhoria dos serviços penais, abrangendo quatro eixos, cuja amplitude aponta alternativas penais, de gestão de problemas e serviços relacionados ao hiperencarceramento, bem como a modernização do sistema penitenciário brasileiro, destaca, no seu terceiro eixo, a humanização das condições carcerárias e a integração social ${ }^{9}$ (BRASIL, 2014, p.7).

A melhoria nesse eixo específico depende da promoção de um modelo intersetorial de políticas públicas de saúde, de educação, de trabalho, de cultura, de esporte, de assistência social e de acesso à justiça. Conforme o Depen, para que esses serviços alcancem as pessoas que encontram-se nos presídios brasileiros, as políticas devem ser implementadas pelos gestores estaduais especializados nas diferentes temáticas sociais governamentais (BRASIL, 2014). Percebe-se assim, que cabe ao Estado cumprir, para que sejam aplicadas de fato, todas as condições e as garantias necessárias para a reintegração, prevenindo o crime e possibilitando o retorno e a convivência em sociedade. É um passo decisivo no reconhecimento de fato de pessoas privadas de liberdade e do egresso como sujeito de direito.

Em relação à representação de pessoas privadas de liberdade, que encontram-se segregadas espacialmente e discriminadas socialmente, é senso comum, devido à problemática de nosso sistema prisional, que ela está frequentemente vinculada a discursos e práticas relacionados a violências e crimes. Separada das normas de convívio social, a população carcerária compõe, muitas vezes, representações perversas, traduzidas em preconceito, estigma e rejeição.

Alessandro Baratta compreende que a conjuntura da prisão impõe condições negativas ao objetivo da ressocialização. Afirma que: Não se pode segregar pessoas e, ao mesmo tempo, pretender a sua reintegração (2007, p.3). O sociólogo defende o uso do conceito de "reintegração social", pois compreende que:

\footnotetext{
... requer a abertura de um processo de comunicação e interação entre a prisão e a sociedade, no qual os cidadãos reclusos se reconheçam na sociedade e esta, por sua vez, se reconheça na prisão.

Os muros da prisão representam uma barreira violenta que separa a sociedade de uma parte de seus próprios problemas e conflitos. Reintegração social (do condenado) significa, antes da modificação do seu mundo de isolamento, a transformação da sociedade que necessita reassumir sua parte de responsabilidade dos problemas e conflitos em que se encontra "segregada" na prisão (Idem,ibidem).
}

\footnotetext{
${ }^{9}$ Considero que o Relatório do INFOPEN de 2014 apresentou análises mais qualitativas dos dados.
} 
Segundo o autor, um dos elementos mais negativos das instituições carcerárias, de fato, é o isolamento do microcosmo prisional do macrocosmo social, simbolizado pelos muros e grades (Idem, ibidem). Afirma que não se pode conseguir a reintegração social do sentenciado através do cumprimento da pena, entretanto se deve buscá-la apesar dela, sendo necessário tornar menos precárias as condições de vida no cárcere, condições essas que dificultam o alcance dessa reintegração (Idem, p.2).

Buscando também contribuir para a desconstrução de olhares e concepções que produzem e reproduzem a lógica classificatória e segregadora de pessoas em situação de privação de liberdade, a narrativa aqui proposta abre espaço, para reflexões e ações junto a grupos estigmatizados que encontram-se nesse espaço de exclusão social.

Diversos documentos manifestam e asseguram ao cidadão a inclusão social e a democratização do acesso aos bens da cultura. Dentre eles, destacam-se: a Declaração Universal dos Direitos Humanos (1948); o Pacto Internacional dos Direitos Econômicos, Sociais e Culturais (1966); a Emenda Constitucional n. ${ }^{\circ} 48$ de 2005, no art. 215 da Constituição Federal; o Plano Nacional de Cultura (2010) e as diretrizes estabelecidas pelo Plano Nacional Setorial de Museus (2010).

O Parecer do Conselho Nacional de Educação / Câmara de Educação Básica nº 4/2010, aprovado, que trata das Diretrizes Nacionais para a oferta de educação para jovens e adultos em situação de privação de liberdade nos estabelecimentos penais ${ }^{10}$, estabelece que:

A prisão, em tese, representa a perda dos direitos civis e políticos. Suspensão, por tempo determinado, do direito do interno ir e vir livremente, de acordo com sua vontade, mas não implica, contudo, a suspensão dos seus direitos ao respeito, à dignidade, à privacidade, à integridade física, psicológica e moral, ao desenvolvimento pessoal e social, espaço onde se insere a prática educacional (BRASIL, 2010, p.13).

Também para consolidar proposta de projeto de sociedade baseada nos princípios da democracia, cidadania e justiça social, cabe ressaltar que o Plano Nacional de Educação em Direitos Humanos, ao tratar de Educação dos Profissionais dos Sistemas de Justiça e Segurança, concebe:

A construção de políticas públicas nas áreas de justiça, segurança e administração penitenciária sob a ótica dos direitos humanos exige uma abordagem integradora, intersetorial e transversal com todas as demais políticas públicas voltadas para a melhoria da qualidade de vida e de promoção da igualdade, na perspectiva do fortalecimento do Estado Democrático de Direito (BRASIL, 2009, p.47).

\footnotetext{
${ }^{10}$ No Decreto no 7.626, de 24/11/2011, da Presidência da República, é instituído o Plano Estratégico de Educação no âmbito do Sistema Prisional - PEESP, que contempla a educação básica na modalidade de educação de jovens e adultos, a educação profissional e tecnológica, e a educação superior.
} 
O desenvolvimento pessoal e social também faz parte dos estudos contemporâneos acerca da função social dos espaços culturais e em especial dos museus, que apontam discussões crescentes nas últimas décadas, onde incluem-se reflexões e problemáticas do uso educativo deste patrimônio cultural. Diferentes práticas em abordagens sociais, culturais e também políticas vêm proporcionando maior interação da sociedade com os espaços museológicos, permitindo multiplicar suas utilizações e ações. Tais práticas permitem diversas experiências históricos-sociais, que contribuem para a compreensão do museu como espaço de formação nos vários campos da ação humana.

O acesso e a formação de públicos nos espaços museais são também considerados compromissos sociais. Para compreensão da função social dos museus, a definição do Conselho Internacional de Museus assegura:

Um museu é uma instituição permanente, sem fins lucrativos, a serviço da sociedade e de seu desenvolvimento, aberta ao público, que adquire, conserva, pesquisa, comunica e expõe o patrimônio material e imaterial da humanidade e de seu meio ambiente para fins de educação, estudo e lazer (ICOM, 2007).

É no potencial educacional do museu que projetos e programas vêm oportunizando práticas inclusivas de democratização do acesso aos bens da cultura a diferentes grupos sociais.

No âmbito dos museus, educadores compartilham da definição de exclusão social compreendida por Gabriela Aidar (2002, p.54), que, refere-se aos processos pelos quais um indivíduo, ou um grupo de indivíduos, encontra-se com acesso limitado aos instrumentos que constituem a vida social e são, por isso, alienados de uma participação plena da sociedade em que vivem. Nesse contexto, seria possível verificar que, no Brasil, grande parcela da sociedade encontra-se excluída dos espaços museológicos, devido a questões econômicas, sociais e também políticas.

Seguindo essa mesma lógica, pode-se considerar que os sujeitos em situação de privação de liberdade dentro do sistema prisional encontram-se inseridos nesse fenômeno de exclusão social. A população carcerária, tendo seus direitos civis e políticos suspensos, seria consequentemente o público mais excluído do espaço do museu e do acesso ao patrimônio cultural. Valdirene Daufemback (2005, p.39) salienta que a prisão parece operar na legitimação dessa rejeição, pois nomeia e localiza um grupo de pessoas que material e simbolicamente não fazem parte dos valores da sociedade. A própria punição por pena de reclusão, muitas vezes, cria visões descriminalizadas de marginalização do indivíduo, operando, reforçando e até ampliando a ideia de rejeição na reintegração social.

Ao considerar que as dinâmicas sociais e as instituições limitam alguns grupos de uma ampla participação na sociedade, Aidar (2002, p.57) argumenta que os museus, como instituições culturais, podem executar um papel numa rede de elementos excludentes, ou por oposição, serem ferramentas para a inclusão social. 
Para prevenir e combater esse complexo quadro de exclusões, é necessária uma atuação em rede que perpasse serviços sociais, civis e governamentais, e meios que possibilitem a participação política, econômica e cultural dos grupos em questão (CHIOVATTO \& AIDAR, 2009, p.3). Nesse sentido, uma atuação em rede contribui imensalmente na desconstrução de visões cristalizadas, superando representações preconceituosas sobre determinados grupos sociais e parcelas da população.

Contribuir para o desenvolvimento social, combater as desigualdades e promover a inclusão de públicos que tradicionalmente não são frequentadores dos espaços museais têm sido também objetivos das ações educativas e culturais realizadas através dos setores e/ou núcleos educativos. Tais ações encontram-se inseridas no campo da educação não-formal ${ }^{11}$ e promovem experiências de diversos públicos no contato com o patrimônio cultural. Esse contato também se dá a partir de ações da Educação Patrimonial, que é:

\begin{abstract}
um instrumento de "alfabetização cultural" que possibilita ao indivíduo fazer a leitura do mundo que o rodeia, levando-o à compreensão do universo sociocultural e da trajetória histórico-temporal em que está inserido. Este processo leva ao reforço da autoestima dos indivíduos e comunidades e à valorização da cultura brasileira, compreendida como múltipla e plural (HORTA et al.,1999, p.6).
\end{abstract}

As ações desenvolvidas pelo Núcleo de Ação Educativa do Museu Histórico de Santa Catarina (NAE/MHSC) visam, além de oportunizar espaços de construção e troca de conhecimentos de forma interativa, garantir uma educação crítica, reflexiva, estética e artística, bem como promover a inclusão sociocultural e a acessibilidade de públicos diversos. As ações têm como objetivo tornar o Museu um espaço de debate, de reconhecimento, de descoberta, de encantamento, que contribua na ampliação e compreensão de novos olhares e leituras de mundo. Pensar, refletir e estabelecer relações dos públicos com os contextos das exposições na contemporaneidade é proporcionar experiências, onde o visitante possa sair do Museu com muito mais indagações do que com respostas prontas e definidas $^{12}$.

No ano de 2009, estabeleceu-se o início do Projeto CONSTRUINDO - desenvolvido pelo NAE/MHSC, com o objetivo de promover o acesso de um grupo de detentos da Penitenciária Estadual de Florianópolis ao patrimônio cultural do Museu Histórico de Santa Catarina (MHSC). O referido

\footnotetext{
${ }^{11}$ Definida não por possuir a mesma carga de formalidade que a educação escolar, mas por possuir intencionalidades e planejamentos prévios. Para aprofundamento do tema, consultar: PARK, Margareth Brandini; FERNANDES, Renata Sieiro; CARCINEL, Amarildo. Palavras-chave em Educação não formal. Holambra (SP): Editora Setembro; Campinas (SP): Unicamp/CMU, 2007.

${ }^{12}$ Creio ser importante mencionar que somente em 2017 foi aprovada a Política Nacional de Educação Museal (PNEM), com o objetivo de nortear a realização das práticas educacionais em instituições museológicas, fortalecer a dimensão educativa em todos os espaços do museu, assim como subsidiar a atuação dos educadores. Segundo a PNEM: $a$ educação museal compreende um processo de múltiplas dimensões de ordem teórica, prática e de planejamento, em permanente diálogo com o museu e a sociedade. https://www.museus.gov.br/wp-content/uploads/2017/06/DocumentoFinal-PNEM1.pdf
} 
Projeto enfatizava a importância do acesso ao patrimônio cultural e da educação patrimonial, como instrumentos de reintegração e inclusão sociocultural de indivíduos submetidos ao regime de privação de liberdade.

Para melhor compreensão do projeto, faz-se necessário contextualizar que desde a década de 1980, a Fundação Catarinense de Cultura (FCC) ${ }^{13}$ mantém um Contrato de Prestação de Serviços de mão de obra com a Penitenciária Estadual de Florianópolis ${ }^{14}$.

A FCC tem como missão valorizar a cultura através de ações que estimulem, promovam e preservem a memória e a produção artística catarinense. Além de executar ações de apoio e desenvolvimento da área cultural do estado de Santa Catarina, estão, sob sua responsabilidade, várias instituições culturais, entre as quais os museus mencionados - MHSC, MIS/SC e MASC - e o Centro Integrado de Cultura Henrique da Silva Fontes (CIC), complexo cultural que abriga museus, teatro, cinema e oficinas culturais.

A Penitenciária Estadual de Florianópolis, instituição com a qual a FCC mantém o referido Contrato, está situada geograficamente vizinha ao CIC. O complexo penitenciário abriga $1628^{15}$ presos do sexo masculino, maiores de 18 anos. Cerca de 357 deles encontram-se em regime semiaberto, que possibilita uma vigilância menos rigorosa, estruturado para que o indivíduo possa trabalhar e estudar. Nesse regime mais brando, encontram-se os presos que progrediram do regime fechado para o semiaberto ou já foram condenados no próprio regime. Permanecem soltos durante o dia ou em trabalho dentro dos muros da unidade prisional (ou externamente, quando autorizados judicialmente). Cada três dias trabalhados resultam em um dia de remissão de pena.

No Contrato firmado entre a FCC e a Penitenciária, estabeleceu-se uma cláusula de liberação de dez reeducandos para prestação de serviços, principalmente no CIC. Os critérios de seleção dos sujeitos para participação no Contrato entre as instituições são de responsabilidade da Penitenciária, a qual indica os reeducandos que não necessitam de acompanhamento e de vigilância de uma agente penitenciário constante. É importante salientar que o CIC também é o maior equipamento multicultural do Estado, com $10.000 \mathrm{~m}^{2}$ de área construída, inserido num terreno de quase $400.000 \mathrm{~m}^{2}$, e que necessita de constante manutenção.

A presença dos reeducandos realizando trabalhos nos espaços culturais do CIC é diária, em serviços de manutenção, tais como: jardinagem, limpeza do estacionamento, pinturas, pequenos reparos, entre outros, sempre sob a supervisão de um técnico do CIC/FCC. Incide, nesse mesmo

\footnotetext{
13 Órgão da Secretaria de Estado de Turismo, Cultura e Esporte / Santa Catarina.

${ }^{14}$ Órgão vinculado ao Departamento de Administração Prisional (DEAP) da Secretaria de Estado Secretaria de Estado da Administração Prisional e Socioeducativa.

${ }^{15}$ Dados informados pela Penitenciária Estadual de Florianópolis em 30/07/2021. A Penitenciária possui capacidade para abrigar 1.387 apenados. Os dados informados ao longo da realização do projeto, alternam-se no decorrer dos anos.
} 
Contrato entre as instituições, as obrigações da FCC, mediante um pagamento mensal, no valor de um salário mínimo, para cada reeducando, nos trabalhos realizados de segunda a sexta-feira, com jornada de trabalho de seis horas diárias e com intervalo para lanche. Apesar de o grupo estar subordinado à Gerência Administrativa do CIC, ele atende às demandas e às necessidades das demais instituições culturais da FCC.

A participação dos integrantes do grupo, cuja faixa etária varia entre 23 e 55 anos de idade, é intermitente, pois podem ser substituídos por condutas de comportamento ou pela liberação do alvará de soltura. O grupo é formado por indivíduos que possuem, em comum, histórias e narrativas de delitos e/ou violências. É esse número relativamente pequeno de pessoas que integravam o grupo participante do Projeto CONSTRUINDO.

A primeira visita realizada pelos reeducandos ao espaço expositivo do Museu Histórico de Santa Catarina (MHSC) foi promovida em agosto de 2009, após uma semana de trabalhos de limpeza efetuados pelo grupo, nos muros, lado externo da edificação do Museu. Localizado no centro de Florianópolis e instalado no Palácio Cruz e Sousa, seu acervo é composto por móveis e objetos diretamente ligados à história política do Estado, sendo um dos maiores patrimônios sua edificação, importante exemplar da arquitetura eclética do final do século XIX. Na ocasião dos serviços prestados, foi criada uma oportunidade de aproximação desse grupo, como público visitante, a fim de conhecer esse patrimônio cultural, como sujeitos de direito. Para tanto, foi solicitada permissão juntamente aos gestores, órgãos e setores responsáveis envolvidos, e assim, após as autorizações, a dispensa dos reeducandos de um período de trabalho e a viabilização de transporte, tornou-se possível concretizar o acesso do grupo a uma visita mediada ao Museu. A visita realizou-se no dia 28 de agosto de 2009, no período vespertino, e contou com a participação de cinco reeducandos. Era a primeira vez que eles entravam no Museu.

Com a repercussão positiva dessa primeira visita ao Museu entre todos os envolvidos e principalmente entre os visitantes, foi possível ampliar o diálogo, sensibilizar e mobilizar técnicos, setores e órgãos envolvidos na ação, com a finalidade de viabilizar a continuidade das visitas ao MHSC. Mas as tratativas e adequações na estrutura das ações não são tão simples, pois somente no ano de 2010 é que novos encontros foram realizados.

O Projeto CONSTRUINDO foi durante sua realização, coordenado e mediado pelas arteeducadoras do Núcleo de Ação Educativa- NAE do MHSC ${ }^{16}$. Cabe informar, que em agosto de 2010,

\footnotetext{
${ }^{16}$ Christiane Castellen e Márcia Lisbôa Carlsson. Outras informações mais detalhadas sobre o NAE e as ações do Projeto constam da publicação: CASTELLEN, Christiane Maria. CONSTRUINDO Ações Culturais em Museus: O patrimônio cultural na reintegração social de pessoas privadas de liberdade. Beau Bassin: Novas Edições Acadêmicas, 2017.
} 
foi oportunizada às coordenadoras, uma visita técnica ao Complexo Penitenciário, proporcionando maior compreensão sobre o contexto prisional em que viviam os participantes do Projeto.

Parcerias, planejamentos, agendas compatíveis, recursos humanos, estrutura e transporte foram viabilizados evidenciando-se a proposição de um Projeto, com visitas sistemáticas do grupo de reeducandos ao Museu, através de encontros mensais. O objetivo inicial tinha como proposta a acessibilidade, a inclusão social, a reintegração e a participação do grupo nas ações educativas socioculturais, oportunizando experiências, percepções, descobertas e apropriações da pluralidade de sentidos e narrativas presentes nas exposições apresentadas no espaço do MHSC. Dessa forma, as condições favoráveis e o caráter educativo do Museu reforçaram e contribuíram para que novos olhares sobre esse público pudessem ampliar oportunidades de realizar ações, em um processo educativo continuado.

No entanto, em 2012, foi possível o desdobramento do Projeto CONSTRUINDO em ações no Museu da Imagem e do Som (MIS/SC) e no Museu de Arte de Santa Catarina (MASC). O MIS/SC possui seu acervo dividido em cinco coleções: Filmes, Som, Imagens Equipamentos e Registros textuais. Já o MASC compõe seu acervo representado por artistas nacionais e estrangeiros e possui obras entre pintura, gravura, escultura, fotografia, objetos e outras. Ambos estão localizados no Centro Integrado de Cultura.

Com o desdobramento do Projeto junto ao MIS/SC e ao MASC, as ações permitiram aos participantes o contato com a pluralidade de acervos e linguagens presentes nas diferentes tipologias dos museus (história, arte, imagem e som), propiciando novas experiências de subjetividade e de produção de conhecimento, a partir da cultura visual e do patrimônio cultural. As visitas mediadas às exposições de longa e curta duração, realizadas nos três museus, permitiram ampliar junto aos participantes, não apenas o repertório visual em diferentes linguagens e técnicas, como também múltiplas abordagens educativas, novas narrativas, histórias e memórias.

A escolha de uma identidade para o Projeto foi amplamente discutida pelo grupo durante os encontros iniciais, mas somente durante o $6^{\circ}$ encontro, com a presença do artista Edgar Bessa, no ano de 2010, decidiu-se por CONSTRUINDO. As reflexões em torno do nome permitiram a compreensão de que ele (o Projeto) possuía a referência de algo que estava em construção, e que essa construção era coletiva, pertencendo a todos os participantes. Quanto ao sufixo INDO, em itálico, no debate com o grupo, foi considerado que sugeria o movimento dos próprios participantes, num processo contínuo de passagem, de fluxo e de mudança. No entanto, somente no ano de 2013, a ideia de um logotipo para o Projeto mobilizou também o interesse de alguns reeducandos, que apresentaram propostas elaboradas para analise e avaliação de todos. Criado pelo reeducando Marco Antônio e definida sob orientação de 
Moysés Lavagnoli - designer gráfico da FCC -, o logotipo é então aprovado pelo grupo em agosto daquele ano.

A metodologia de trabalho escolhida e empregada no Projeto, pelas arte-educadoras do NAE/MHSC, não teve a preocupação do rigor científico inerente ao campo acadêmico, pois diante do impossível, tateava-se o imprevisível. Nesse sentido, para o desenvolvimento do Projeto, optouse pela utilização do aporte metodológico da pesquisa-ação de Michel Thiollent (1996, p. 16). É um tipo de pesquisa social com base empírica que: é concebida e realizada em estreita associação com uma ação ou com a resolução de um problema coletivo. Pesquisadores e participantes representativos da situação estavam envolvidos de modo cooperativo e participativo. De outros suportes teóricos escolhidos, destaca-se conceitos de: "mediação", em Lev S. Vygotsky (1989); de “dialogia”, em Mikhail Bakhtin (1992; 2003); de “relações de poder”, em Michael Foucault (2003; 2012; 2014); de "educação patrimonial”, em Maria de Lourdes Parreiras Horta (1999); de "objeto gerador", em Francisco Régis Lopes Ramos (2004); de "inclusão social aplicada a práticas dos museus", em Gabriela Aidar (2002); e de "políticas educacionais em museus", em Maria Helena Rosa Barbosa (2009).

No que diz respeito à existência de um projeto dessa natureza, de alguma forma o pesquisador interfere na vida dos sujeitos, e torna-se imprescindível, segundo Yves de La Taille (2008, p.271), a necessidade de serem ponderados dois princípios que inspiram a ética na pesquisa com seres humanos: 1) a dignidade inerente à pessoa humana, e 2) a liberdade.

Assim, faz-se necessário esclarecer que, para fins de registrar as ações desenvolvidas durante as visitas, instrumentos e estratégias elaborados foram compartilhados e autorizados pelos participantes do Projeto. Conforme orientação específica, o termo de consentimento nominado de "Declaração" foi redigido, com os devidos esclarecimentos a respeito do uso de imagens e materiais produzidos no percurso do Projeto, assim como da divulgação de informações sobre ele.

No que tange à exposição das imagens pessoais, tomando o devido cuidado a fim de não constranger os participantes, bem como de resguardá-los da curiosidade geral, os registros fotográficos privilegiaram o grupo em interação nas ações do Projeto, preferencialmente de costas e potencializando a ação em seu contexto, mas não o sujeito identificado dessa ação. Mantevese dessa forma, o sigilo dos participantes.

Os procedimentos para a atuação durante a visita do grupo foram selecionados a partir de objetos e conteúdos geradores de conhecimento e reflexão presentes nas exposições. Tais procedimentos proporcionaram a elaboração de ações flexíveis e compartilhadas com os participantes, como forma de estabelecer relações construtivas com o grupo, assim como iniciativas comunitárias. Inicialmente, esse público visitante recebia com certa estranheza e desconfiança a oportunidade de 
escolherem e dialogarem com liberdade de expressão. O estranhamento era compreensivo por estarem os participantes habituados e inseridos em uma instituição penal, permeada por segurança, rigor e controle. No entanto, as ações e atividades propostas no espaço do Museu foram acolhidas com curiosidade, respeito e responsabilidade. Diálogos, trocas e interações no grupo mobilizaram posturas mais espontâneas e de confiança em encontros posteriores.

A riqueza de proposições potencializada nos projetos educativos pode ser observada a partir de alguns títulos das exposições temporárias visitadas: Isso não posso contar; Pintar o futuro; Do Conceito e da Afeição; Contaminações: Linhas da infância; Grupo de Risco; Na Pele; O Tesouro do Morro da Igreja; Pinceladas de Luz; Fotografando o Silêncio; Ritos, Ditos e Ditados: Memórias Inventadas; Guerra do Contestado: 100 anos de memórias e narrativas; Gravar: técnica e expressão; Além de 3x4; Guerreiros do bronze ao aço; O coração no Olho; Na sombra de uma origem; Diálogo entre Eros, Psique e Thanatos; Palavra em Movimento; Gambiarra Sonora; Universo das Coisas Incontáveis. Essa, assim como as demais exposições, permitiram potencializar diálogos e reflexões qualitativas.

As visitas do grupo nas exposições proporcionaram experiências, vivências, memórias e ressignificações individuais e coletivas. Possibilitaram também ampliar percepções, imaginações e reflexões, assim como, fomentar conhecimentos, expressões e produções criativas. Foi possível perceber a importância das ações vinculadas ao patrimônio cultural, a partir dos diálogos dos participantes que foram registrados nos encontros, que constam dos arquivos do NAE:

(1) "Precisei ser preso para entrar no museu” (2010).

(2) "Me senti maravilhado!" (2011).

(3)"Aprendi coisas que não tinha conhecimento (2012).

(4) “Os olhos não se cansam de olhar, nem os ouvidos de ouvir” (2013).

(5) "Nos ajuda a conhecermos melhor nossa cultura, nosso estado, artistas (2015).

(6) “Quanto mais revela, dá mais curiosidade!” (2016).

Foram realizados 48 encontros do Projeto CONSTRUINDO com o grupo de reeducandos no decorrer dos anos de 2009 a 2018, totalizando 62 exposições visitadas (de longa e curta duração), em três museus da FCC, sendo 27 visitas mediadas no MHSC, 12 visitas no MIS/SC e 7 visitas no MASC ${ }^{17}$.

Sempre que possível, durante as visitas foram oportunizados encontros presenciais com artistas, curadores/as das exposições, assim como com historiadores/as, pesquisadores/as e cineasta, que permitiram o estabelecimento de diálogos e relações sobre suas experiências, suas subjetividades e seus

\footnotetext{
${ }^{17}$ Dos 48 encontros mencionados, 2 deles foram realizados em 2 museus não pertencentes à FCC. Em 30/04/2010, houve um encontro no Museu Victor Meirelles (MVM), que está geograficamente vizinho ao MHSC. Outro encontro também foi realizado em 10/06/2016, no Museu de Arqueologia e Etnologia Professor Oswaldo Rodrigues Cabral (MArquE), vinculado à Universidade Federal de Santa Catarina/UFSC, por convite do Setor Pedagógico do MArquE aos participantes do Projeto CONSTRUINDO.
} 
processos criativos. Debates e reflexões sobre temas contemporâneos nessas práticas sociais promoveram formas de sociabilidade e o fortalecimento de posicionamentos individuais diante do grupo sobre percepções e descobertas. Foram promovidos ao todo 14 encontros presenciais, que contaram com a participação de 18 convidados.

Já as oficinas temáticas e as vivências em oficinas práticas foram estruturadas conjugando relações com as visitas nas exposições, sendo elaboradas diferentes metodologias, com procedimentos que possibilitaram experiências significativas e interativas. Foi possível perceber, algumas vezes, o receio de alguns reeducandos no início dos procedimentos, talvez por acreditarem que realizavam essas ações de forma incorreta, ou mesmo por inibição. Mas o fortalecimento de vínculos entre os participantes e o respeito às individualidades permitiram ao grupo maior autoconfiança para a realização dos trabalhos. O respeito aliado ao reconhecimento de limitações individuais e coletivas minimizaram situações de vergonha ou desconfiança.

Foi possível, também, observar a valorização das ações e o envolvimento de todos os participantes com as temáticas propostas e com os materiais disponibilizados. Tais materiais proporcionaram experiências em diferentes linguagens, bem como a descoberta de potencialidades e a autovalorização de suas próprias possibilidades, como percebe-se nestas falas , extraídas dos arquivos do NAE:

(1) “Foi a primeira vez que peguei um pincel e tinta de verdade” (2010).

(2) "Percebi que abriu a vontade de voltar a conhecer e frequentar mais o mundo da arte e da memória do nosso passado." (2011).

(3)“A gente sabe fazer [...] basta acreditarem na gente!” ((2014).

(4) “O que seria sem esse momento de rir todos juntos” (2015).

(5) "Experiência nova para a gente que está trancado” (2016).

O momento das oficinas foi considerado, por alguns, muito importante, pois propiciava maior interação e descontração nas atividades. Foram elaboradas 29 vivências em diversas oficinas práticas: pintura, recorte e colagem, desenho, gravura, fotografia, música, palavra, narrativas, retrato e desenho com teatro de sombra, sendo 3 oficinas temáticas de patrimônio cultural e história da fotografia.

Projeções de filmes que dialogavam com as temáticas das exposições também permitiram experiências na linguagem cinematográfica. Assim, foram realizadas 3 exibições durante os encontros: O tesouro do Morro da Igreja, Victor Meirelles - Quadros da História e Narradores de Javé.

Em todos os encontros, havia um espaço de "rememoração", possibilitando reavivar memórias das experiências, dos diálogos e das reflexões em relação às visitas realizadas nas exposições anteriores. Foi possível perceber relações qualitativas de reconhecimento com os repertórios temáticos, narrativos e visuais das exposições e dos patrimônios culturais visitados. 
Nos horários dos encontros em visitas aos museus, as proibições e limitações de suas vidas cotidianas apontavam possibilidades de outros significados, como demonstrou o comentário de um dos participantes: Neste momento sou um homem livre! (NAE, 2010). Havia compromisso e assiduidade com os calendários e as ações do Projeto, assim como também havia espera especulativa, na expectativa de novos encontros, por parte de todos os envolvidos. Os reeducandos desejavam ser avisados com antecedência, pois a agenda de horários de visita aos museus transformava-se em referência, sendo considerada em relação aos compromissos com as visitas de seus familiares, e também porque desejavam estar bem apresentados nos encontros. Eis a fala de um dos participantes: Se vocês marcarem o dia do próximo encontro, a gente não marca visita com a família neste dia pra poder estar aqui (NAE, 2014).

Entre os instrumentos e estratégias que foram elaborados a fim de registrar as ações do Projeto estão: relatórios descritivos dos encontros, registros fotográficos, registros das atividades e produções nas oficinas, captação de imagens em vídeos e relatos de opiniões dos participantes (reeducandos, artistas, mediadores, psicólogas(os), servidores). Diversos materiais impressos, como convites de exposições, folders e catálogos, reproduções de obras de arte, foram doados, quando disponibilizados pelas exposições.

A rotatividade dos integrantes do grupo, devido à intermitência de sua participação substituição por conduta de comportamento ou liberação do alvará de soltura -, impôs ao Projeto uma adaptação constante. Alguns indivíduos participaram no decorrer de um ano ou mais, outros, em apenas dois ou mais encontros, sendo que, para a grande maioria, foi a primeira vez que entravam em um museu.

O Projeto proporcionou a participação de 144 reeducandos, sendo que retornaram ao Museu, quando em liberdade, $50 \%$ dos participantes no ano de 2010. No decorrer dos anos, eventualmente, alguns participantes retornaram apenas para conversar com as arte-educadoras, mencionando sobre a importância da experiência vivida, e do desejo de que o Projeto prosperasse. Houve depoimentos de terem visitado o museu com seus familiares, colegas e ou namorada.

O Projeto CONSTRUINDO contemplou, além do desenvolvimento de ações integradas com as equipes dos núcleos educativos dos museus mencionados, o fortalecimento de práticas ampliadoras do processo de inclusão e do acesso ao patrimônio cultural para públicos excluídos socialmente.

Havia o compartilhamento das ações desenvolvidas pelas arte-educadoras do NAE/MHSC, com servidores de setores específicos da FCC, que foram fundamentais para a realização e a manutenção do Projeto. Informações sobre as ações do Projeto também foram compartilhadas com funcionários da Penitenciária, proporcionando interações construtivas entre sujeitos e contextos diferentes. Estavam entre eles: diretor da penitenciária, chefe de segurança, psicólogas(os), assistente social, coordenadoras 
da escola do Complexo Penitenciário, entre outros. Houve a presença de alguns desses técnicos em três encontros, a fim de acompanhar as visitas do Projeto, possibilitando assim, que também eles visitassem/conhecessem os museus e sua função social.

Foi possível ampliar a divulgação sobre as ações do Projeto com a representante do Programa de Educação nas Unidades Prisionais e Unidades de Intervenção da Secretaria de Estado da Educação de Santa Catarina.

Os reeducandos consideravam importante o compartilhamento das ações do Projeto. Sobre esse desejo deles, destaca-se o comentário registrado de um dos participantes: Quero que o projeto seja divulgado para olharem diferente para nós (NAE, 2010).

A FCC e suas casas vinculadas, assim como a Penitenciária Estadual de Florianópolis, são instituições mantidas e administradas pelo poder público estadual, e estão, também, sujeitas à sazonalidade de suas gestões. Foi nesse contexto que o Projeto CONSTRUINDO envolveu sujeitos históricos diversos (reeducandos, servidores, técnicos, educadores, coordenadores, gestores), que encontravam-se inseridos em campos de atuação com atribuições completamente diferentes. Em ambas as instituições foram possíveis diálogos sobre a relevância do Projeto, assegurando sua realização e continuidade até o ano de 2018.

Ao serem promovidas ações em que os reeducandos puderam vivenciar e dialogar nos espaços museológicos, em contato com os códigos e significados potencializados pelos objetos do patrimônio cultural, acredita-se ter favorecido não só o reconhecimento desses espaços como lugares de direito e de cidadania, mas também de significações pessoais e comunitárias. Para Milene Chiovato, as ações de leitura, significação e apropriação dos objetos museais apontam ao mesmo tempo para o sujeito que lê e para o mundo ao seu redor, estabelecendo um fluxo de significação entre objeto, sujeito e mundo (CHIOVATTO in AIDAR \& CHIOVATTO, 2010).

Ao longo do percurso de desenvolvimento do Projeto, ficou evidente e perceptível a importância e a valorização atribuídas pelos participantes a esse espaço/tempo aberto às visitas, narrativas, reflexões e propostas. Foi verbalizado por muitos participantes o desejo de compartilhar a experiência vivida no espaço do Museu com seus familiares e com os demais colegas encarcerados, por compreenderem a importância educativa e cultural. Da mesma forma, reconhecem que a falta de políticas públicas e de ações educativas e culturais para crianças e jovens em regiões periféricas, contribuem para o quadro de exclusão social atual.

Percebe-se que a educação patrimonial contribui não apenas no "reforço da autoestima dos indivíduos e comunidades", como aponta Horta (1999), mas pode ir além de informação e conhecimento, como menciona Martins: 
Trata-se de um processo de consciência de ser cidadão, de ser responsável pelo todo elaborado de um mundo ou parte dele. Representa uma ação não apenas para preservação, para a defesa da memória da história, do respeito e das referências tão necessárias para ser o que somos: pessoas de um lugar, com referências, pertencimentos bem peculiares que por sermos da raça humana, somos ao mesmo momento, locais e universais (MARTINS, 2012, p.190).

Creio que é a partir de nossa compreensão do potencial de desenvolvimento humano que existe nos espaços de encarceramento e através do exercício de uma cidadania ativa, que poderemos também avançar na aplicabilidade das demandas sociais. Com a implementação de políticas públicas sociais (programas, projetos e ações), juntamente com a valorização, apropriação e ressignificação do patrimônio cultural, é possível também garantir a reintegração e a inclusão sociocultural de indivíduos privados de liberdade.

Faz-se necessário destacar que o contexto político-institucional nas implementações de políticas públicas com vistas à democratização, à inclusão social e à acessibilidade dos diferentes públicos nos espaços educacionais e culturais, em diferentes níveis das esferas do poder público (federal, estadual e municipal), foi fundamental e influenciador para o desenvolvimento do Projeto.

O Projeto CONSTRUINDO, foi no ano de 2015 inserido no Plano Museológico (documento fundamental para a sistematização do trabalho institucional) do Museu Histórico de Santa Catarina, sendo normatizado como um projeto de atuação sistemática. No entanto, no ano de 2019, algumas dificuldades apresentaram-se para a continuidade do Projeto, que agravaram-se no ano de 2020 por conta da pandemia do COVID19 no Brasil, mantendo-se desde então, suspensos todos os encontros.

Cabe mencionar ainda que, com base nas ações desenvolvidas pelo MHSC, um novo desdobramento realizou-se dentro do Projeto CONSTRUINDO no ano de 2017. Tratou-se da integração de novos procedimentos junto a um grupo de pacientes do Hospital de Custódia e Tratamento Psiquiátrico - HCTP, vinculados ao DEAP. Com a mesma proposta de encontros mensais, foram promovidos o atendimento de 6 a 8 pacientes em média (sempre os mesmos participantes a cada encontro, com poucas alternâncias), acompanhados de psicólogas(os), assistentes sociais e ou agentes penais. Somaram-se ao todo, 17 encontros realizados no museu até outubro de 2019. Apesar de estarem no mesmo guarda-chuva do Projeto CONSTRUINDO, planejamentos, estratégias e ações são diferenciados com os pacientes do HCTP. Tais ações merecem um relato mais aprofundado e uma análise específica a parte. As visitas com os pacientes do HCTP estão também suspensas desde o início da pandemia do COVID19. 


\title{
2 CONSIDERAÇÕES FINAIS
}

Para dialogar em um contexto marcado por tensões, regras e exclusões, como as presentes no sistema prisional brasileiro, ações com vistas à democratização, à reintegração social e à inclusão sociocultural de pessoas privadas de liberdade articularam experiências educativas e culturais com resultados positivos. A partir do patrimônio cultural presente nos espaços museológicos do estado de Santa Catarina, ações favoráveis oportunizaram um trabalho interdisciplinar com equipes multidisciplinares e humanistas, por meio de projetos culturais, em parceria, que incluíram procedimentos na própria estrutura do Estado.

Creio que os resultados produzidos pelo Projeto CONSTRUINDO, possam contribuir na visibilidade de ações de reintegração e inclusão sociocultural junto ao complexo fenômeno de aprisionamento, na medida em que apontam condições favoráveis para a realização de procedimentos possíveis para diversos profissionais de diferentes campos de atuação: educação, cultura, segurança pública, administração pública e a própria sociedade.

O Projeto viabilizou iniciativas que extrapolaram a ação interna da instituição museológica e incorporou diversas experiências histórico-culturais. Ele abriu novas intervenções, possibilitando a renovação de conceitos e práticas tanto para as instituições envolvidas (FCC e Penitenciária) como para a formação docente, as universidades e os próprios museus.

É possível que ações dessa amplitude oportunizem pautas de reivindicação no plano institucional, legal e social, em torno de demandas e realizações que proporcionem a reintegração à sociedade de indivíduos em situação de privação de liberdade. As relações contemporâneas, ao reivindicarem novos olhares, promovem o rompimento de paradigmas, provocando novas práticas sociais, que contribuem na busca de alternativas para problemas sociais tão complexos como os do sistema carcerário no Brasil.

Gabriela Figurelli enfatiza que:

\begin{abstract}
Através do patrimônio cultural, o museu viabiliza a construção social da memória e a potencializa como ferramenta para a percepção crítica da sociedade e a promoção de melhorias sociais. Com o auxílio do patrimônio cultural, o museu desempenha o papel de mediador, articulando público, patrimônio e espaço, na busca pela construção, ressignificação e apropriação das identidades que auxiliam no processo de conscientização social (FIGURELLI, 2010, P,34).
\end{abstract}

Assim, compreender a importância do desenvolvimento de ações inclusivas para diferentes sujeitos sociais em contato com o patrimônio cultural possibilita reconhecê-lo como fonte de conhecimento, portador de significados, lugar de apropriação, de identidade, de pertencimento.

São os órgãos públicos os proponentes e reguladores de "lugares culturais", e nesses lugares são constituídas práticas sociais. Compondo muitas vezes o que Rogério Proença Leite (2004, p.39) 
chamou de "cartografia do poder", o autor observa que os lugares singularizam-se principalmente pelas representações e práticas construídas pelas pessoas que neles interagem. Nesse sentido, tornase vital a mobilização de interlocutores diferenciados nos planos institucionais, contribuindo para legitimar práticas e projetos participativos em parceria, com o intuito de incorporar novos sujeitos na construção de uma nova realidade. Fortalecendo a ideia de que é possível pensar um mundo novo, com alternativas e possibilidades, Boaventura de Sousa Santos (SANTOS, 2007, p.37-38) afirma que devemos buscar credibilizar, ampliar simbolicamente as possibilidades de vê-lo a partir do presente, dando visibilidade a experiências possíveis, que não estão dadas porque não existem alternativas para isso, mas são possíveis e já existem como emergência.

Penso ser consenso de todos que inúmeros desafios apresentam-se para toda a sociedade. Para nós, gestores e servidores públicos (das diferentes áreas), o desafio é refletir sobre uma política atenta para a diversidade e complexidade que compõem não só os espaços institucionais, mas os espaços de sociabilidade na contemporaneidade.

Conforme Boaventura Santos,

[...] é preciso fazer transgressões. Buscamos o novo nos interstícios, entre as realidades, [...] de nossa sociabilidade, que estão articulados de maneira muito complexa. Precisamos migrar de um campo a outro, de um estrato a outro, de uma linguagem a outra; a transdisciplinaridade é, em parte isso. Temos ainda de buscar conceitos que venham de outros conhecimentos (Idem, p.48).

Baratta defende que:

... não se pode resolver a questão carcerária aprisionando pessoas, conservando o cárcere como instituição fechada. Porque o lugar da solução do problema carcerário é - e diz respeito a-toda sociedade (2007, p.9).

Desejo que a experiência dos participantes do Projeto CONSTRUINDO possa contribuir na reflexão sobre parcerias possíveis e em práticas efetivas de reintegração de pessoas em situação de privação de liberdade. Desejo também que essa experiência possa abrir portas, derrubando estigmas, minimizando o processo de exclusão, ampliando discussões e apontando oportunidades em contextos com múltiplas dimensões sobre políticas públicas, culturais, sociais e educacionais, com vistas à reintegração e inclusão sociocultural do sujeito em privação de liberdade em toda a sua complexidade. 


\section{REFERÊNCIAS BIBLIOGRÁFICAS}

AIDAR, Gabriela. Museus e inclusão social. Ciências \& Letras n.31. Revista da Faculdade Porto Alegrense de Educação, Ciências e Letras. Porto Alegre: FAPA, 2002.

. Estabelecendo diálogos: as ações do Programa de Inclusão Sociocultural. In: AIDAR, G. \& CHIOVATTO, M. Percorrer e registrar: reflexões sobre a ação educativa extramuros da Pinacoteca do Estado de São Paulo. São Paulo: Pinacoteca do Estado, 2010.

BAKHTIN, Mikhail. Marxismo e Filosofia da Linguagem. 9.ed. São Paulo: Ucitec, 1992.

. Estética da Criação Verbal. Introdução e tradução do russo de Paulo Bezerra, 4.ed. São Paulo: Martins Fontes, 2003.

BARATTA, Alessandro. Ressocialização ou controle social: uma abordagem crítica da "reintegração social" do sentenciado. Alemanha: Universidade de Saarland, 2007. Disponível em: <http://www.ceuma.br/portal/wp-content/uploads/2014/06/BIBLIOGRAFIA.pdf>. Acesso em 03.mar. 2017.

BRASIL. Atos Internacionais. Pacto Internacional sobre Direitos Econômicos, Sociais e Culturais. Promulgação. Disponível em: 〈http://www.planalto.gov.br/ccivil_03/decreto/19901994/d0591.htm>. Acesso em: 25 jun. 2013.

. Cartilha do Reeducando. Conselho Nacional de Justiça, 2010. Disponível

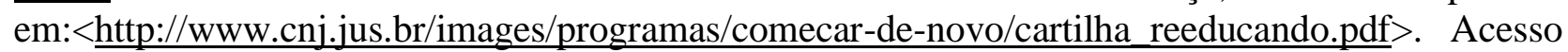
em: 27 jun. 2010.

. Constituição da República Federativa do Brasil de 1988. Disponível em:

<http://www.planalto.gov.br/ccivil_03/constituicao/constituicao >. Acesso em: 30 maio 2013.

. Decreto no 7.626, de 24 de novembro de 2011. Institui o Plano Estratégico de Educação no âmbito do Sistema Prisional. Disponível em:

<http://www.planalto.gov.br/ccivil_03/_Ato2011-2014/2011/Decreto/D7626.htm>. Acesso em: 16 nov. 2015.

. Emenda Constitucional $\mathbf{n}^{\mathbf{0}} \mathbf{4 8}$, de 10 de agosto de 2005. Disponível em:

<http://www.planalto.gov.br/ccivil_03/constituicao/emendas/emc/emc48.htm>. Acesso em: 25 jun. 2013.

. Lei no 12.343, de 2 de dezembro de 2010. Institui o Plano Nacional de Cultura.

Brasília, DF. Disponível em: < http://www.planalto.gov.br/ccivil_03/_ato2007-

2010/2010/lei/l12343.htm>. Acesso em: 07 jul. 2012.

. Levantamento Nacional de Informações Penitenciárias (Infopen), junho 2014.

Departamento Penitenciário Nacional (Depen) / Ministério da Justiça. Brasília, DF. Disponível em: http://www.cnj.jus.br/files/conteudo/arquivo/2015/11/080f04f01d5b0efebfbcf06d050dc a34.pdf>. Acesso em: 17 nov. 2015.

Levantamento Nacional de Informações Penitenciárias (Infopen), junho 2016. Departamento Penitenciário Nacional (Depen) / Ministério da Justiça. Brasília, DF. Disponível em: <https://www.justica.gov.br/news/ha-726-712-pessoas-presas-nobrasil/relatorio_2016_junho.pdf>. Acesso em: 06 ago. 2018 
. Levantamento Nacional de Informações Penitenciárias (Infopen), julho a dezembro 2020. Departamento Penitenciário Nacional (Depen) / Ministério da Justiça. Brasília, DF. Disponível em: <https://www.gov.br/depen/pt-br/sisdepen >. Acesso em: 03 ago. 2021

. Parecer CNE/CEB N 2/2010. Ministério da Educação e Cultura. Diretrizes Nacionais para a oferta de educação de jovens e adultos em situação de privação de liberdade nos estabelecimentos penais. In: Portal do MEC - Diretrizes para a Educação Básica, Brasília, DF, 2010.Disponível em: <http://portal.mec.gov.br/index.php?option=com docman\&view=download\&alias $=4445$ -pceb004-10\&category_slug=abril-2010-pdf\&Itemid=30192>. Acesso em: 15 jan. 2015.

Plano Nacional de Educação em Direitos Humanos / Comitê Nacional de Educação em Direitos Humanos. Brasília: Secretaria Especial dos Direitos Humanos, Ministério da Educação, Ministério da Justiça, UNESCO, 2009.

. Plano Nacional Setorial de Museus - 2010/2020. Ministério da Cultura, Instituto Brasileiro de Museus. Brasília, DF: MinC / Ibram, 2010. Disponível em: <http://www.museus.gov.br/wp-content/uploads/2012/03/PSNM-Versao-Web.pdf>. Acesso em: 07 mar. 2013.

CASTEllen, Christiane Maria. CONSTRUINDO Ações Culturais em Museus: O patrimônio cultural na reintegração social de pessoas privadas de liberdade. Beau Bassin: Novas Edições Acadêmicas, 2017.

. Ações Culturais em Museus para Pessoas Privadas de Liberdade: Projeto CONSTRUINDO. In: CALABRE, Lia [et al.]. Anais do VII Seminário Internacional de Políticas Culturais, 17 a 20 de maio de 2016. Rio de Janeiro: Fundação Casa de Rui Barbosa, 2016. Disponível em: $<$ http://culturadigital.br/politicaculturalcasaderuibarbosa/files/2016/06/Anais-do-VIISemin\%C3\%A1rio-Int-Pol-Cult.pdf $>$.

O Educador frente a outras realidades: educação patrimonial para pessoas privadas de liberdade do sistema carcerário. In: FONSECA DA SILVA, Maria Cristina da Rosa (Org.) Cadernos de docência: contribuições para a formação em artes visuais. Florianópolis: AAESC, 2015. p.39-62. CHIOVATTO, Milene; AIDAR, Gabriela. Arte+. São Paulo: Pinacoteca do Estado, 2007.

CHIOVATTO, Milene. Ações extramuros: diminuindo barreiras. In AIDAR, G. \& CHIOVATTO, M. Percorrer e registrar: reflexões sobre a ação educativa extramuros da Pinacoteca do Estado de São Paulo. São Paulo: Pinacoteca do Estado, 2010.

DAUFEMBACK, Valdirene. Condições de aprisionamento e condições de aprendizagem de encarcerados. 2005. 240p. Dissertação (Mestrado em Psicologia) - Programa de Pós-raduação em Psicologia. Universidade Federal de Santa Catarina, Florianópolis, 2005.

FIGURELli, Gabriela. O Público Esquecido pelo Serviço Educativo: estudo de caso sobre um programa educativo direcionado aos funcionários de museu. 2010. 165p. Dissertação (Mestrado em Museologia) - Curso de Mestrado em Museologia, Faculdade de Arquitetura, Urbanismo, Geografia e Artes. Universidade Lusófona de Humanidades e Tecnologias, Lisboa, 2010. Disponível em: <http://www.museologia-portugal.net/files/upload/mestrados/gabriela_figurelli.pdf $>$.

FOUCAULT, Michel. Microfísica do Poder. 18.ed., Rio de Janeiro: Graal, 2003. . Segurança, Penalidade e Prisão. In: MOTTA, Manoel Barros da (Org.). Coleção Ditos \& Escritos VIII. Tradução: Vera Lucia Avellar Ribeiro. Rio de Janeiro: Forense Universitária, 2012. 


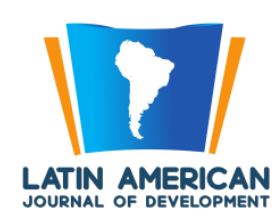

. Vigiar e punir: nascimento da prisão. Tradução de Raquel Ramalhete. 42.ed., Petrópolis (RJ): Vozes, 2014.

HORTA, Maria de Lourdes Parreiras. Guia básico de educação patrimonial. Brasília: IPHAN / Museu Imperial, 1999.

ICOM - International Council of Museum. Museum Definition - 2007. In: ICOM - Development of the Museum Definition according to ICOM Statutes (2007-1946). Disponível em: <http;//icom.museum/hist_def_eng.html $>$. Acesso em: 18 set. 2010.

LA TAILLE, Yves de. Ética em pesquisa com seres humanos: dignidade e liberdade. In: GUERRIERO, I. C. Z., SCHMIDT, M. L. S., ZICKER F. (Orgs). Ética nas pesquisas em ciências humanas e sociais na saúde. São Paulo: Aderaldo \& Rothschild, 2008.

LEITE, Rogério Proença. Lugares da política e consumo dos lugares: nação e patrimônio cultural. In: Contra-usos da cidade: lugares e espaços públicos na experiência urbana contemporânea. Campinas (SP): Editora da UNICAMP; Aracajú (SE): Editora UFS, 2004. p.34-95.

MARTINS, José Clerton de Oliveira. Tempos sociais acelerados, patrimônio cultural em risco. In: BRASILEIRO, M. D. S., MEDINA, J. C. C., and CORIOLANO, L. N. (Orgs). Turismo, cultura e desenvolvimento [online]. Campina Grande: EDUEPB, 2012. p.169-193. Disponível em: <http://books.scielo.org/id/7y7r5/pdf/brasileiro-9788578791940-09.pdf>. Acesso em: 18 fev. 2015.

NAE/MHSC. Relatórios do Projeto CONSTRUINDO: Núcleo de Ação Educativa do Museu Histórico de Santa Catarina (2009-2019). Florianópolis: MHSC.

PARK, Margareth Brandini; FERNANDES, Renata Sieiro; CARCINEL, Amarildo. Palavras-chave em Educação não formal. Holambra (SP): Editora Setembro; Campinas (SP): Unicamp/CMU, 2007.

RAMOS, Francisco Régis Lopes. A danação do objeto: O museu no ensino de História. Chapecó: Argos, 2004.

ROSA BARBOSA, Maria Helena. Museus de Arte: desafios contemporâneos para a adoção de políticas educacionais. 2009. 256p. Dissertação (Mestrado em Artes Visuais) - Programa de PósGraduação em Artes Visuais, Universidade do Estado de Santa Catarina, Florianópolis, 2009.

SANTOS, Boaventura de Sousa. A sociologia das Ausências e a Sociologia das Emergências: para uma ecologia de saberes. In: Renovar a teoria crítica e reinventar a emancipação humana. São Paulo: Boitempo, 2007.

THIOLLENT, Michel. Metodologia da Pesquisa-Ação. São Paulo: Cortez, 1996. VYGOTSKY, Lev. Pensamento e linguagem. 2.ed. São Paulo: Martins Fontes, 1989. 


\section{REFERÊNCIAS ELETRÔNICAS}

\section{REFERENCIAS ELETRÔNICAS}

http://www.cnj.jus.br/images/programas/comecar-de-novo/cartilha_reeducando.pdf

https://www.cnmp.mp.br/portal/relatoriosbi/sistema-prisional-em-numeros

http://dados.mj.gov.br/dataset/infopen-levantamento-nacional-de-informacoes-penitenciarias

http://www.deap.sc.gov.br

http://www.fcc.sc.gov.br/

https://www.gov.br/depen/pt-br/assuntos/noticias/depen-lanca-infopen-com-dados-de-dezembro-de2019

https://www.gov.br/depen/pt-br/sisdepen/mais-informacoes/relatorios-infopen

http://www.masc.sc.gov.br/

http://www.mhsc.sc.gov.br/

http://www.mis.sc.gov.br/

https://www.museus.gov.br/wp-content/uploads/2017/06/Documento-Final-PNEM1.pdf

http://www.onu.org.br/a-onu-em-acao/a-onu-e-os-direitos-humanos/

http://www.planalto.gov.br/ccivil_03/_ato2004-2006/2006/lei/111343.htm

http://www.planalto.gov.br/ccivil_03/_Ato2007-2010/2009/Lei/L11904.htm 